\title{
Choosing the International Standards Organization's Interlibrary Loan Protocol (ISO) or Preserving the Status Quo?
}

\author{
Mary E. Piorun \\ Jane Fama
}

\begin{abstract}
This paper chronicles an analysis of (1) interlibrary loan workflow and data and (2) how management used this information to make a decision on the ISO question. The National Library of Medicine adopted portions of the ISO Protocol for DOCLINE® 2004 as a response to the medical interlibrary loan community. ILLiad®, which is already ISO compliant, has responded by announcing an upcoming release of an ISO compatible version of their management system in 2005. If libraries choose to convert to ISO, one DOCLINE function, Loansome Doc ${ }^{\circledR}$, will no longer be available. The question: Is the enhanced functionality with seamless DOCLINE and ILLiad interaction worth the effort that it will take to create and run a new Loansome Doc workflow? doi:10.1300/J474v17n01_08 [Article copies available for a fee from The Haworth Document Delivery Service: 1-800-HAWORTH. E-mail address. <docdelivery@haworthpress.com> Website: $<$ http://www.HaworthPress.com> (C) 2007 by The Haworth Press, Inc. All rights reserved.]
\end{abstract}

Mary E. Piorun is Associate Director, Systems (E-mail: Mary.Piorun@umassmed. edu); and Jane Fama is Associate Director, Access Services (E-mail: Jane.Fama@ umassmed.edu), both at Lamar Soutter Library, UMASS Medical School, 55 Lake Avenue North, Worcester, MA 01655.

OCLC ILLiad Resource Sharing Management Software is a registered trademark of Atlas Systems, Inc and Online Computer Library Corporation. DOCLINE and Loansome Doc are registered trademarks of the U.S. National Library of Medicine.

Journal of Interlibrary Loan, Document Delivery \& Electronic Reserve Vol, 17(1/2) 2007

Available online at http://jildd.haworthpress.com

(C) 2007 by .The Haworth Press, Inc. All rights reserved. doi:10.1300/J474v17n01_08 
KEYWORDS. DOCLINE, ILLiad, ISO, loansome doc, interlibrary loan, medical libraries, process analysis, process improvement

\section{BACKGROUND}

The Lamar Soutter Library (LSL), at the University of Massachusetts Medical School (UMMS), is a medium-sized academic health sciences library with 48 FTE. It holds the contract for the National Network of Libraries of Medicine, New England Region. UMMS is the only statefunded medical school in Massachusetts and includes graduate schools of nursing and biomedical sciences. LSL's collection totals 290,000 volumes, of which 210,000 are the print journal collection. LSL has used the ILLiad interlibrary loan management system since fall 2000.

Since its creation, ILLiad has been designed to work with OCLC. With each upgrade since 2000 , the lines between the ILLiad software and the OCLC system have been gradually disappearing without having to use the International Standards Organization's interlibrary loan protocol (ISO). The relationship between ILLiad and OCLC became so strong that ILLiad has become an OCLC product. Using the ILLiad management system makes it practically unnecessary to access the OCLC system directly. This level of development and cooperation has not been matched with the DOCLINE interlibrary loan system. Users have to toggle between ILLiad and DOCLINE, and are required to manually initiate system downloads and uploads. Using ISO may be way to achieve the high level of integration for DOCLINE that is already available for OCLC.

The ISO interlibrary loan Protocol allows for the seamless communication between compatible interlibrary loan systems. It promises to: (1) reduce processing time and (2) improve communication between libraries and patrons by offering real time status. ILLiad and OCLC are ISO compliant. DOCLINE has implemented a portion of the ISO protocol. ILLiad expects to release a version that will work with DOCLINE in the fall of 2005. However, Loansome Doc (LD), a subset of the DOCLINE system, is not ISO compliant, and there are no plans to implement the ISO protocol in the future. Therefore, if a library chooses to use the ISO protocol to process all other DOCLINE requests (traditional lending and borrowing), it will be required to change the way it processes Lonesome Doc requests.

As New England's regional medical library (RML), LSL is committed to provide services to medical and health science professionals who 
do not have access to a library. The Loansome Doc program is a cornerstone of these services. It is important to LSL that it continues to meet the information needs of this community.

\section{PROBLEM}

Libraries have waited for an improvement in communications between DOCLINE and ILLiad that would simplify workflow. However, the question that arises for management is: Will the functionality achieved with seamless DOCLINE and ILLiad interaction be worth the effort that it will take to create new workflows, especially in the Loansome Doc process?

In analyzing the problem, we must consider implementing ISO throughout the entire interlibrary loan operation. Specifically we must consider the following points:

- Improvements in processing time.

- Impact on staff.

- Impact on Lonesome Doc users.

- Time required implementing a new Loansome Doc workflow.

\section{WORK LOAD AND STAFFING}

The LSL is a member of both the DOCLINE and OCLC networks. The work is distributed between the two networks: 40/60 lending, and 80/20 borrowing. LSL has consistently been a "net lender." The department has 1.5 FTE staff. LSL also participates in the Loansome Doc program through the National Library of Medicine (NLM).

Annual Workload-Three Year Average

\begin{tabular}{lcc}
\hline & Requests & Work Load (\%) \\
\hline Lending & 19,283 & $88 \%$ \\
Borrowing & 1,688 & $8 \%$ \\
Loansome Doc & 929 & $4 \%$ \\
Total & 21,900 & $100 \%$ \\
\hline
\end{tabular}

We decided that a comparison of the "before" and "after" workflow would be the best way to determine whether implementing ISO would 
be beneficial. We created flow-charts of the borrowing, lending, and Loansome Doc processes. At each step, we assigned the number of minutes, which we obtained either from the ILLiad system's time stamp or from an actual timing test of a random sample of requests. Then we flow-charted the expected workflow after ISO implementation on both DOCLINE and OCLC systems.

After reviewing the comparative data, it was combined with the more subjective analysis of the effect on service and the way patrons order Lonesome Doc requests.

The following assumptions were made for this study:

- General

- Data for the time study was obtained from a random sample of 30 borrowing, lending, and Loansome Doc requests from fiscal year 2005 (July, 2004-June, 2005).

- Annual workload figures are based on the average of the last three years.

${ }^{\circ}$ Results are rounded to the nearest whole minute.

${ }^{\circ}$ Study is focused on article processing.

- Lending

${ }^{\circ}$ Lending requests are processed in batches of 50 .

- Borrowing

- The time it takes another library to fill our borrowing requests or Lonesome Doc requests was not part of our time study.

- Loansome Doc

${ }^{\circ}$ LD requests are pulled and copied in the same batch load as traditional lending requests. Our time estimates are based on processing four requests at a time.

- All Lonesome Doc are processed in a batch until we determine that a request needs to be transferred. At that point, it is handled as a single borrow requests.

\section{CURRENT LENDING WORKFLOW}

Preprocessing. Staff logon to DOCLINE to pick up pending requests at least twice a day. They select and copy the records using Windows keystrokes (ctrl-a, ctrl-c) and return to ILLiad, where they import the requests as a batch. The requests are deposited in the ILLiad lending 
processing queue, the same queue to which the OCLC requests are automatically downloaded every two hours. Batch Cycle Time: 2 Minutes.

Request Review. Each request is individually reviewed for maximum cost, delivery method, and shipping address. Pull slips are then printed. Batch Cycle Time: 18 Minutes.

Request Processing. Staff takes pull slips to the stacks to retrieve materials for scanning, photocopying, or mailing. Materials are delivered per customer request (Ariel, e-mail, fax, mail). After the delivery process, library staff marks the transactions "complete" in ILLiad and the requests are queued for billing. If the material is never located, the request is cancelled in ILLiad. Batch Cycle Time: 180 Minutes.

Request Completion. OCLC requests will be updated to reflect final status in the next automatic batch upload. However, DOCLINE requests must be updated manually by toggling back and forth between ILLiad and DOCLINE. In ILLiad, staff cut-and-paste records to be brought back to DOCLINE and updated in a batch mode. They must do this category-by-category (e.g., finished requests, rejected for NOS, rejected for NOT, etc.). Batch Cycle Time: 2 Minutes.

Total Batch Cycle Time: 202 Minutes or 3.4 Hours.

\section{LENDING WORKFLOW AFTER ISO}

Preprocessing. Requests are automatically downloaded from both DOCLINE and OCLC into ILLiad in real time. Batch Cycle Time: 0 Minutes.

Request Review. Each request is individually reviewed for maximum cost, delivery method, and shipping address. Pull slips are then printed. Batch Cycle Time: 18 Minutes.

Request Processing. Staff takes pull slips to the stacks to retrieve materials for scanning, photocopying, or mailing. Materials are delivered per customer request (Ariel, e-mail, fax, mail). After the delivery process, library staff marks the transactions "complete" in ILLiad, and the requests are queued for billing. If the material is never located, the request is cancelled in ILLiad. Batch Cycle Time: 180 Minutes.

Request Completion. Both OCLC and DOCLINE requests will be updated in their respective systems to reflect finished status in real time. Batch Cycle Time: O Minutes.

Total Batch Cycle Time: 198 Minutes or 3.3 Hours. 


\section{CURRENT BORROWING WORKFLOW}

Prepossessing. Staff logon to ILLiad to review rsequests, which patrons have entered via their ILLiad accounts. The first step in processing a request is to confirm billing information. Also at this time, staff checks the LSL's online catalog to verify that we do not hold the title. Cycle Time: 1 Minute.

Ordering. Staff has two options when filling requests. They can choose to order through DOCLINE or OCLC based on the materials requested and the potential lenders.

DOCLINE: Staff logon to DOCLINE and obtain the PMID, the unique identifier for the article, if the patron does not provide it. With DOCLINE running in the background, the PMID is entered into the ILLiad record and saved. ILLiad then uses the PMID to create the order in DOCLINE. Staff completes the order manually and confirmation data is then imported back into the ILLiad system. These steps require staff to continually toggling back and forth between ILLiad and DOCLINE. Cycle Time: 3 Minutes.

OCLC: From within ILLiad, staff searches the OCLC system for the title to identify potential lenders, create a work form and send the request. Cycle Time: 20 Minutes.

Receipt and Completion. Staff receives material from the lending library and search for the transaction in ILLiad. They mark the request "received" and notify the patron that the material is available. DOCLINE requests do not require any final updating on the DOCLINE system. OCLC requests are updated in the next scheduled automatic update. Cycle Time: 1 Minute.

Total Cycle Time DOCLINE: 5 Minutes.

Total Cycle Time OCLC: 22 Minutes.

\section{BORROWING WORKFLOW AFTER ISO}

Prepossessing. Staff logon to ILLiad to review requests, which patrons have entered via their ILLiad accounts. The first step in processing a request is to confirm billing information. Also at this time, staff checks the LSL's online catalog to verify that we do not hold the title. Cycle Time: 1 Minute.

\section{Ordering}

DOCLINE: Staff logon to DOCLINE and obtain the PMID, the unique identifier for the article, if the patron does not provide it. The PMID is 
then entered into the ILLiad record and saved. The order is then transmitted to DOCLINE via the ISO protocol. Cycle Time: 1 Minute.

OCLC: From within ILLiad, staff search for the title to identify potential lenders, create a work form, and send the request. Cycle Time: 20 Minutes.

Receipt and Completion. Staff receives materials from the lending library and search for the transaction in ILLiad. They mark the request "received" and notify the patron that the material is available. DOCLINE requests do not require any final updating on the DOCLINE system. OCLC requests are updated in real time. Cycle Time: 1 Minute.

Total Cycle Time DOCLINE: 3 Minutes.

Total Cycle Time OCLC: 22 Minutes.

\section{CURRENT LOANSOME DOC WORKFLOW}

Preprocessing. Staff acknowledges and prints out requests from DOCLINE and imports them in to ILLiad. The requests, by default, are imported into the Borrowing module. Staff reviews each request individually, verifying billing information, and looking for special instructions. Once the request is saved, it is routed to ILLiad's Document Delivery (DocDel) module. Once the request is in the DocDel module, the status of the request is manually changed to "In Document Delivery Stack Searching." Batch Cycle Time: 5 Minutes.

Request Review. Request printouts are individually reviewed to see if LSL hold the title. If LSL has the title, the request is batched with the traditional lending requests for pull and copy. If LSL does not own the title, the request is transferred on to another library to fill on our behalf. (See Transfers.) Batch Cycle Time: I Minute.

Request Processing. Staff takes pull slips to the stacks to retrieve materials for scanning, photocopying, or mailing. Materials are delivered per customer request (e-mail, fax, mail). After the delivery process, library staff marks the transactions "complete" in ILLiad, and the requests are queued for billing. If the material is never located, the request is queued for transfer. (See Transfers.) Batch Cycle Time: 18 Minutes.

Request Completion. Using the original Lonesome Doc printout, staff $\log$ on to DOCLINE and manually mark each request as completed. Batch Cycle Time: I Minute.

Transfers. To transfer the request, the status in ILLiad is marked as transferred; staff then log into DOCLINE and transfer the request. The 
request is automatically routed to a supplying library that owns the required volume. Batch Cycle Time: 10 Minutes.

Transfer Completion. Once the supplying library has notified us that the request has been filled, staff marks the transaction "complete" in ILLiad and DOCLINE. The request is then queued for billing. If the article is never located, the request is cancelled in ILLiad and DOCLINE and the user is notified. Batch Cycle Time: 3 Minutes.

Total Batch Cycle Time Filled: 25 Minutes.

Total Batch Cycle Time Transfers: 19 Minutes.

\section{LOANSOME DOC WORKFLOW AFTER ISO}

As stated earlier, the Loansome Doc sub-system is not ISO compliant. The protocol was designed to work library-to-library and does not take into account patron-initiated requests. As a result, if we convert to ISO and want to continue serving our Lonesome Doc customers, we will have to register as a "Document Delivery Service" with PubMed and no longer use the Lonesome Doc system in any way. This would require us contacting each of our Lonesome Doc patrons and explaining the changes: (1) logging in and authentication, (2) the new ordering procedures, and (3) viewing order history and status.

Another major change, that affects the library, is if the title is not owned or located, the request can no longer be transferred to another library through the DOCLINE Lonesome Doc System. Our policy will be to fill the request internally using DOCLINE, as if it were a typical borrow request from any internal library patron. Prior to ISO implementation, this work would have been done by the DOCLINE Lonesome Doc system automatically.

To begin the search and request process, the user must first logon to PubMed through the library's Web site as an ILLiad user. Once authenticated is completed, the patron can search and submit requests.

Preprocessing. The requests, by default, appear in the ILLiad Borrowing module, along with regular borrowing requests. Library staff reviews each request to identify those that are Lonesome Doc requests. They verify billing information, and look for any special instructions. Once the request is saved, it is routed to ILLiad's Document Delivery module. The requests are printed. Batch Cycle Time: 3 Minutes.

Request Processing/Completion. Staff takes pull slips to the stacks to retrieve materials for scanning, photocopying, or mailing. Materials are delivered per customer request (e-mail, fax, mail). After delivery, li- 
brary staff mark the transactions "complete" in ILLiad, and the requests are queued for billing, or if the material is never located, the request is transferred to the Borrowing module to be filled as a typical borrow request. Batch Cycle Time: 18 Minutes.

Internal Transfers. From the Borrowing module, DOCLINE transmits the order via the ISO protocol. The original request was submitted with a PMID; therefore, no additional search is needed. Cycle Time: 1 Minute.

Transfer Completion, Staff receives the article from the lending library and search for the transaction in ILLiad borrowing. The request is then routed to DocDel (necessary for internal billing procedures), marked "received," and queued for billing. If the material is never located, the patron is notified, and the request is routed to DocDel in ILLiad, and cancelled. DOCLINE requests do not require any final updating on the DOCLINE system. Cycle Time: 3 Minutes.

Total Batch Cycle Time Filled: 21 Minutes

Total Cycle Time Transfers: 25 Minutes

\section{Summary of Processing Time in Minutes}

\begin{tabular}{lcccl}
\hline & Pre ISO & Post ISO & Difference & $\%$ of Time Change \\
\hline Lending (Batch of 50) & 202 & 198 & 4 & $2 \%$ Decrease \\
$\begin{array}{l}\text { Borrowing (Single Request) } \\
\quad \text { DOCLINE }\end{array}$ & 5 & 3 & 2 & $40 \%$ Decrease \\
$\quad$ OCLC & 22 & 22 & 0 & No Change \\
Loansome Doc (Batch of 4) & & & & \\
$\quad$ Fills (3) & 25 & 21 & 4 & $16 \%$ Decrease \\
$\quad$ Transfers (1) & 19 & 25 & -6 & $31 \%$ Increase \\
\hline
\end{tabular}

\section{ANALYSIS}

Lending, borrowing, and Lonesome Doc processing are analyzed individually, taking into consideration each function's system utilization and workload.

\section{Lending}

Lending comprises $88 \%(19,283)$ of the total workload; $40 \%(7,713)$ of these requests are received through DOCLINE and the remaining $60 \%(11,570)$ are OCLC requests.

The measurable difference pre- and post-ISO is found at the beginning and end of the lending processes. Because of real time communication 
with ISO, manual downloading and updating of DOCLINE requests are eliminated. This results in a time saving of 4 minutes for every 50 DOCLINE requests or 6 minutes a day for our daily average of approximately 75 requests. This is a $2 \%$ savings in lending processing time. In addition, OCLC requests are updated in real time instead of through an automated schedule every two hours, which can sometime fail.

The elimination of manual downloads and uploads not only saves 6 minute per day in processing time, but also has less quantifiable effects such as (1) reducing opportunities for mistakes (i.e., remembering to update in a timely manner), (2) doing away with multiple system logins, and (3) simplifying training for new employees. In addition, our fellow libraries are able to get real time status of their requests.

\section{Borrowing}

Borrowing comprises $8 \%(1,688)$ of total workload; $80 \%(1,350)$ of these requests are sent through DOCLINE and the remaining 20\% (338) are OCLC requests.

The time-consuming work in borrowing consists of verifying citations (obtaining a UI) and determining if LSL owns the material. These tasks are outside of the ISO protocol. However, ISO protocol does reduce the number of steps required to place a DOCLINE order, producing a time saving of two minutes per request. With an average of six requests per day, this equals a time saving of 12 minutes or $40 \%$ in borrowing processing.

There is no change in the OCLC borrow process. We still need to identify potential lenders and create work forms in OCLC.

\section{Loansome Doc}

Loansome Doc, a sub-system of DOCLINE, comprises 4\% (929) of the total workload. Currently $70 \%$ (650) of the requests are filled in-house and 30\% (279) are transferred to other libraries. With an average of three Lonesome Doc requests filled in-house per day, this equals a savings of 3 minutes or $16 \%$ in Lonesome Doc processing.

The $30 \%$ (279) of transfer requests that can no longer be passed on through the DOCLINE/LD system, (an average of 1 per day), will be filled as if they were originating from our library patrons. This extra step requires our staff to initiate a new request in DOCLINE* via the ILLiad borrow system. This change increases Lonesome Doc processing time by 6 minutes or $31 \%$. Our policy will be to fill these requests 
though DOCLINE because DOCLINE requesting takes 1 minute, compared with OCLC's 22 minutes.

The net result on processing time for Lonesome Doc requests is an increase of 2 minutes per day.

\section{RECOMMENDATION}

We started this project by asking, "Will the functionality we achieve with seamless DOCLINE and ILLiad interaction is worth the effort that it will take to create new workflows, especially in the Lonesome Doc process?"

Our analysis leads us to answer, "yes-it is worth the extra effort to implement ISO." The objective was to achieve a high level of integration between interlibrary loan systems (ILLiad, DOCLINE, OCLC and Loansome Doc) without compromising processing time and service. Based on the above analysis, we think this objective is possible for the following reasons:

\section{Improvement in Processing Time}

Our workflow analysis indicates that ISO implementation will result in the following savings per function, per day: lending 6 minutes, borrowing 12 minutes, and Lonesome Doc 2 minutes. Therefore, we could save up to 16 minutes per day or 80 minutes a week in total. We realize that processing through ISO will simplify the operation for all requests, except the Lonesome Doc requests. However, Lonesome Doc requests make up only $4 \%$ (929) of the workload. What we would gain minimizes the loss.

\section{Impact on Staff}

The impact on staff is minimal and, overall, the elimination of steps in the workflow is a positive change. A transition period, while new procedures are written, tested, and implemented is expected. However, since staff has been asking for greater communication between the interlibrary loan systems, we will be able to obtain staff buy-in.

\section{Impact on Lonesome Doc Users}

The impact on our current Lonesome Doc users is significant. They will be required to change how they search for and request articles. The procedure will be different, but it should be straightforward and easily adopted. The most important consideration is that this change will not 
limit or impede service in any way. Patrons will continue to receive articles in a timely manner.

\section{Time to Implement a New Lonesome Doc Workflow}

There is no significant time investment required to implement the new Lonesome Doc workflow. Requests will be diverted to the borrow module, which staff are currently using. There are no new skills to learn. However, we estimate that it could take up to three weeks to create documentation, contact Lonesome Doc patrons and review their options. We are aware that these changes may result in losing some Lonesome Doc patrons, and it is not clear at this time what impact it will have on recruiting new customers. It will be incumbent on staff to market this service in a positive note emphasizing our continued commitment to meet the needs of health professionals.

In addition to these reasons, as an RML, we feel it is important to test new technologies and make recommendations to other libraries in our region. It is also important that we promote future interoperability by adopting accepted interlibrary loan standards. Therefore, we recommended that LSL adopt the ISO protocol, once the ILLiad system is compatible with DOCLINE's implementation of the protocol.

System implementation will involve setup, configuration, and testing. A conservative estimate calls for a five-week schedule, with minimal downtime from start to finish.

It is important to acknowledge that total seamless interoperability will not be achieved with the ISO protocol. There is still the need to verify citations and holdings. Despite this shortcoming, ISO is a step in the right direction.

Update: In the 16 months since this article was written, the Lamar Soutter Library Loansome Doc customer base doubled. The impact this increase would have had on borrowing using the ISO protocol led the Library to reconsider implementation. Many other libraries faced the same issue, but only three entered into implementation. This lack of participation contributed to the National Library of Medicine's decision on January 26, 2007 to abandon support of the ISO protocol citing the high cost of maintenance and implementation. Although this first attempt to link Docline and interlibrary loan management systems seamlessly was not sucessful, it is important for the NLM to recognize the need to reduce overall processing time by continuing to work with third party software. 


\section{BIBLIOGRAPHY}

Atlas Systems Incorporated. "OCLC ILLiad Administrative Suite-Implémentation Guide." Version 6.5 - Revised 29 October 2004. 12 April 2005. <http://216.54.31. 120/Documentation/OCLCILLiadImplementationGuide.pdf>.

Davis, Mark, Nicholas Aquilano, Richard Chase. Fundamentals of Operations Management. Fourth Edition. Boston: McGraw-Hill, 2003.

Jackson, Mary. "Using Standards to Share Resources Globally: Implementing the ISO interlibrary loan Protocol." 7 May 1998. 12 April 2005. <http://www.arl.org/ access/naildd/ipig/res/portugal.shtml>.

Norton, Melanie, Stover, Michelle. "OCLC ILLiad." Journal of the Medical Library Association 91(3) (July 2003). 18 July 2005. <http://www.pubmedcentral.nih. gov>. PMCID: 164409 .

U.S. National Library of Medicine. "FAQ: DOCLINE-ISO interlibrary loan Protocol." 6 July 2004. 12 April 2005.<http://www.nlm.nih.gov/services/doc_iso_ill__protocol. html>.

U.S. National Library of Medicine. "FAQ: DOCLINE-ISO interlibrary loan Protocol and Loansome Doc" 27 October 2004. July 14, 2005. <http://www.nlm.nih.gov/services/ doc_iso_ill_LD.html>.

U.S. National Library of Medicine. "FAQ: DOCLINE-ISO interlibrary loan Protocol Conversion." 12 November 2004. 21 April 2005. <http://nlm.nih.gov/services/doc _iso_ill_library.html $>$.

U.S. National Library of Medicine. "FAQ: DOCLINE-ISO interlibrary loan Protocol Issues." 18 November 2004. 12 April 2005. <http://www.nlm.nih.gov/services/ doc_iso_ill_issues.html>.

\section{INFORMAL INTERVIEWS}

Powell, Genie. Interview with Jane Fama and Mary Piorun, 6 April 2005.

$$
\text { doi: } 10.1300 / J 474 \text { v17n01_08 }
$$

